\title{
Collective impact of scrap, random breakdown, overtime and discontinuous issuing on batch production planning in a supply-chain environment
}

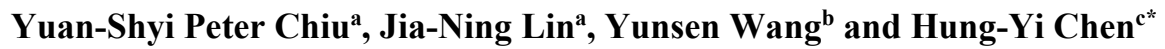

${ }^{a}$ Department of Industrial Engineering and Management, Chaoyang University of Technology, Taiwan

${ }^{b}$ Dept. of Accounting \& Finance, Feliciano School of Business, Montclair State University, Montclair, New Jersey, USA

'Department of Information Management, Chaoyang University of Technology, Taiwan

A B S T R A C T

Article history:

Received June 18, 2021

Received in revised format July

20, 2021

Accepted September 222021

Available online

September 222021

Keywords:

Production planning

Replenishing runtime

Overtime

Scrap

Random breakdowns

Supply chain

\begin{abstract}
This research explores the collective impact of overtime, random breakdown, discontinuous issuing rule, and scrap on batch production planning in a supply-chain environment. In today's global business environment, manufacturing firms encounter numerous operational challenges. Externally, they must promptly satisfy the customers' various requests, while internally, they must cautiously manage several inevitable issues in the fabrication process. These issues might be concerned with scrap, random breakdown, etc. Resolving such issues is crucial for meeting the due dates of customers' orders, adhering to the expected manufacturing schedules, product quality, and minimizing the total fabrication-transportation-inventory costs. The study develops a model to characterize the system's features mentioned above and assist the manufacturers with batch fabrication planning. The model proposes a solution process with an algorithm seeking an optimal runtime for the system. Additionally, it gives a numerical illustration depicting the collective and individual impacts of these special features on the operating policy and other performance indices. This model and the research findings can facilitate manufacturers' decision-making for green batch fabrication and enhance competitive advantage.
\end{abstract}

(C) 2022 Growing Science Ltd. All rights reserved.

\section{Introduction}

In the present-day global business environment, one critical operational challenge manufacturing firm encounter is to satisfy various requests of the customers promptly. An overtime option often is chosen to expedite or smooth the constricted fabrication schedules. Mumford and Dowrick (1994) studied the effect of wage negotiation on internal profit, overtime, and mixed labor in the environment of the unionized industry. The variations of wages, work hours, different labor forces, and profit measurements were examined. The authors intended to offer and test for efficient wage models that consisted of the bargaining model. Özdamar et al. (2002) studied the joint effects of setup time and overtime on the operating policy of a capacitated batch fabrication problem, wherein the batch sizes of several product families were planned over a finite time horizon. The setup times rather than cost were considered to have an important effect on the problem, and the limited regular time and overtime capacities were considered. The authors intended to simultaneously minimize stock holding costs and overtime usages in the occurrences of capacity bottlenecks. To solve the problem, the authors used the tabu search, genetic algorithm, and simulated annealing. The results were compared with the existing works using heuristics. DemiRel and Taskan (2012) explored the intangible and tangible benefits of the Turkish textile firms that implemented strategies of shifts and overtime via the performance measurement systems. A model was proposed in a fuzzy multiple criteria decision-making environment to help in evaluating firms' performance and assessing their strong and weak areas. Campbell (2017) developed a prescheduling-overtime staffing framework in the environment of the service industry. The study started with building a

* Corresponding author

E-mail address: hychen39@gm.cyut.edu.tw (H.-Y.Chen)

(C) 2022 Growing Science Ltd. All rights reserved.

doi: $10.5267 /$ j.uscm.2021.9.009 
model for the single-shift cases and evaluated its benefits from the time-stage overtime strategy, which involving lower costs and less unscheduled overtime usages. Then, the study extended to the development of a multi-shift model, which considered minimum rest and consecutive working hours in between shifts. Improvement of demand forecasts, workers' availability, management of open shifts, and overtime scheduling were taken into consideration in the study. Additional works (Fontinha et al., 2019; Aouam and Kumar, 2019; Jeunet and Bou Orm, 2020; Johansson et al., 2020; Soriano et al., 2020; Abdul Halim et al., 2021; Chiu et al., 2021; Keyvanshokooh et al., 2021) study the impact of diverse overtime strategies on the corporation and fabrication management.

In a real supply chain environment, a discontinuous stock issuing rule, particularly the multiple shipments, is often requested by the retailers/customers to optimize their limited storage space. Hill (1997) investigated the general replenishment-delivery policy for a production-inventory coordinated system in a single-producer, single-customer environment, wherein the single fabrication batch with an increasing factor was involved. Kreng and Chen (2007) examined a collaborated manufacturer-distributor-retailer supply chain system to decide the optimal order and shipment sizes, and the number of deliveries. Two integrated models were developed for the three-echelon supply chains, and the connection of the two models was investigated to show that collaboration of all parties may result in the optimal shipment size and hence reduce the total system cost significantly. Pal et al. (2012) considered a multiproduct supply chain system with multi-suppliers, single-manufacturer, and multi-retailers, wherein only single raw material was supplied by each supplier to the manufacturer to produce multiple end items and then distribute to various retailers. The authors intended to maximize the integrated system profit with optimal raw materials' ordering sizes. Giri and Sharma (2017) studied a single-producer, single-retailer integrated fabrication-inventory system, wherein, the producer uses a generalized shipment plan to distribute end products to meet the retailer's orders. Due to the imperfection in the fabrication, an inspection action was used by the retailer upon receiving each delivery. The authors used the renewal reward theory and optimization approach to minimize the total annual system costs with optimal decisions. They further extended their model to examine inspection errors and extra investment for dropping ordering costs at the retailer side. Other works (Ravulakollu et al., 2018; Brahmi et al., 2020; Chiu et al., 2020; Nogueira et al., 2020; Frank et al., 2021; Martins et al., 2021; Ongcunaruk et al., 2021) explored the influence of various product shipping policies on diverse types of (intra-)supply chain environments.

Moreover, manufacturing firms must cautiously manage several internal inevitable issues in the fabrication process regarding random scrap and breakdown. Resolving such issues is crucial for adhering to the expected production schedules along with product quality and minimizing the total fabrication-transportation-inventory costs. Gunasekaran et al. (1991) investigated a fabrication-inventory system with multiproduct, multiple stages and facilities, and studied the impact of machine failure on the system's optimal lot sizes and total costs. The authors proposed a solution method for seeking the optimal lot sizes and illustrated their model/method via an example. Makis and Fung (1998) explored the joint influence of random breakdowns and inspections on an economic manufacturing quantity-based system. The researchers obtained the formula of the expected annual cost function, then by minimizing the obtained function, they jointly decided the optimal inspection policies and fabrication lot-size. Wee et al. (2007) studied the joint influence of defective products and allowable shortage on the optimal replenishment policy. The authors assumed that all identified faulty items are removed from the finished lot, and the customers accept the backorder. An algorithm and numerical illustration show the solution of their model along with its performance. Ullah and Kang (2014) investigated the joint effect of inspection, rework, and scrap on the work-in-process and the batch-size decision. The researchers used the mathematical modeling to explore the effect of the abovementioned characteristics on their problem's operating decision. Additional works (Adazabra et al., 2018; Chiu et al., 2019; Klašnja et al., 2019; Assia et al., 2020; Salehi Amiri et al., 2020; Tolooie et al., 2020; Villacís and Burneo, 2020; Gera, 2021) focused on manufacturing/supply-chain operations with diverse aspects of defective goods and unreliable equipment along with their consequent controlling actions. This research explores the collective impact of overtime, scrap, random breakdown, and discontinuous issuing rule on batch production planning. It intends to assist manufacturers in meeting the due dates of customers' orders, adhering to the expected fabrication schedules along with product quality, and minimizing their total fabrication-transportation-inventory costs. Our model and research findings will enable the manufacturers to enhance their competitive advantage. As little prior works have focused on this collective impact on batch production planning, the present study links the gap.

\section{The Proposed Batch Production Planning Problem}

This study examines a batch production planning problem incorporating an overtime plan, random scrap and breakdown, and a discontinuous stock issuing rule. To promptly meet annual demand $\lambda$ of a specific product, a batch production plan with an extra $\alpha_{1}$ proportion of overtime output is established. The proposed overtime option has a speedup rate $P_{1 \mathrm{~A}}$ per year along with its connecting setup cost $K_{\mathrm{A}}$ and unit production cost $C_{\mathrm{A}}$. The following relationship expresses overtime relevant parameters and the standard variables:

$$
\begin{aligned}
& C_{\mathrm{A}}=\left(1+\alpha_{3}\right) C \\
& P_{1 \mathrm{~A}}=\left(1+\alpha_{1}\right) P_{1} \\
& K_{\mathrm{A}}=\left(1+\alpha_{2}\right) K
\end{aligned}
$$


where $P_{1}, K$, and $C$ are the regular rate, setup, and unit costs (i.e., without implementing overtime option); $\alpha_{2}$ and $\alpha_{3}$ denote the cost increase proportion due to overtime implementation. For instance, $\alpha_{1}=0.2$ represents the overtime output rate is $20 \%$ more than the standard rate; and $\alpha_{2}$ (or $\left.\alpha_{3}\right)=0.25$ means the corresponding overtime relating cost is $25 \%$ more expensive than its usual cost. Further, owing to different uncontrollable reasons the process may produce $x$ proportion of scrap/defective products randomly, at a rate $d_{1 \mathrm{~A}}$ (where $d_{1 \mathrm{~A}}=x P_{1 \mathrm{~A}}$ ). To avoid the stock-out conditions, we assume that $\left(P_{1 \mathrm{~A}}-d_{1 \mathrm{~A}}-\lambda\right)>0$. Further, the machine during its running time may randomly break down, and a Poisson distributed average rate of $\beta$ per year is assumed. When the equipment fails, the repair work starts right away, and the making of the unfinished batch restarts instantly once the equipment is restored. Upon completing batch fabrication, $n$ fixed-quantity deliveries to the buyer are made at a fixed-time interval $t_{\mathrm{nA}}^{\prime}$ in $t_{2 \mathrm{~A}}^{\prime}$. Additional notation utilized in this work is listed in Appendix A. The following two distinct cases are investigated due to the randomness of machine breakdown:

\subsection{Case 1: A random breakdown happens (that is $t<t_{1 A}$ )}

The level of finished goods in case 1 is displayed in Fig. 1. When the production equipment fails, the level of finished goods comes up to $H_{0}$, and after the equipment is mended, it piles up to $H$ when the uptime ends. Then, finished products are depleting discontinuously in the issuing time $t_{2 \mathrm{~A}}^{\prime}$.

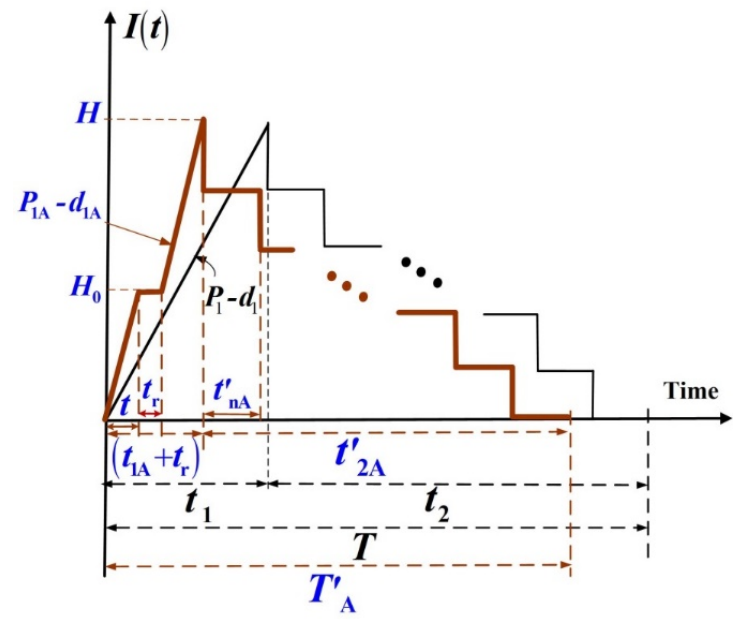

Fig. 1. The finished product level in case one of the proposed problem with a random breakdown, scrap, and overtime option (in brown) compared to the same problem with scrap only (black)

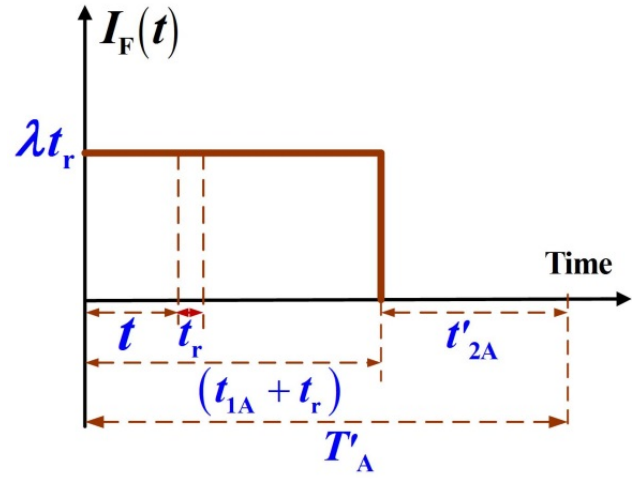

Fig. 2. The safety product level in case 1

The safety product level in case 1 is depicted in Fig. 2. Owing to the additional product demand in $t_{\mathrm{r}}$ in case $1, \lambda t_{\mathrm{r}}$ must be included in the completed batch and issued to the client in $t_{2 \mathrm{~A}}^{\prime}$. The scrap product level in case 1 is shown in Fig. 3 . The scrap accumulates to $d_{1 \mathrm{~A}} t$ when a random failure occurs, and after the failure is fixed, it rises to $d_{1 \mathrm{~A}} t_{1 \mathrm{~A}}$.

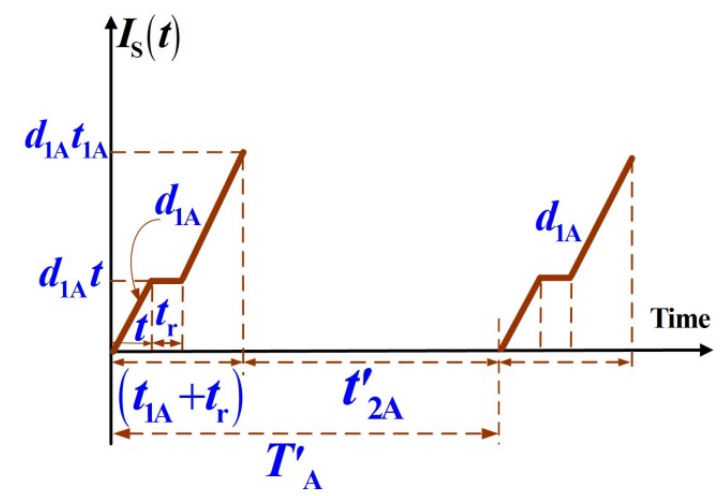

Fig. 3. The scrap product level in case 1 of the proposed problem

According to the description of the problem along with observing the Fig. 1 to Fig. 3 mentioned above, the following formulas are gained:

$$
t_{1 \mathrm{~A}}=\frac{H_{1}}{P_{1 \mathrm{~A}}-d_{1 \mathrm{~A}}}=\frac{Q}{P_{1 \mathrm{~A}}}
$$




$$
\begin{aligned}
& d_{1 \mathrm{~A}} t_{1 \mathrm{~A}}=x Q=t_{1 \mathrm{~A}}\left(x P_{1 \mathrm{~A}}\right) \\
& H_{0}=t\left(P_{1 \mathrm{~A}}-d_{1 \mathrm{~A}}\right) \\
& T^{\prime}{ }_{\mathrm{A}}=t_{1 \mathrm{~A}}+t^{\prime}{ }_{2 \mathrm{~A}}+t_{\mathrm{r}}=\frac{Q(1-x)}{\lambda}+t_{\mathrm{r}} \\
& t^{\prime}{ }_{2 \mathrm{~A}}=T^{\prime}{ }_{\mathrm{A}}-\left(t_{1 \mathrm{~A}}+t_{\mathrm{r}}\right) \\
& H=\left(P_{1 \mathrm{~A}}-d_{1 \mathrm{~A}}\right) t_{1 \mathrm{~A}}+\lambda t_{r}
\end{aligned}
$$

The finished product level in issuing time $t_{2 \mathrm{~A}}^{\prime}$ in case 1 is exhibited in Fig. 4 . The total stocks in $t_{2 \mathrm{~A}}^{\prime}$ can be calculated by Eq. (10).

$$
\left(\sum_{i=1}^{n-1} i\right) H\left(t_{2 \mathrm{~A}}^{\prime}\right)\left(\frac{1}{n^{2}}\right)=\frac{n(n-1)}{2} H\left(t^{\prime}{ }_{2 \mathrm{~A}}\right)\left(\frac{1}{n^{2}}\right)=H\left(t^{\prime}{ }_{2 \mathrm{~A}}\right)\left(\frac{n-1}{2 n}\right)
$$

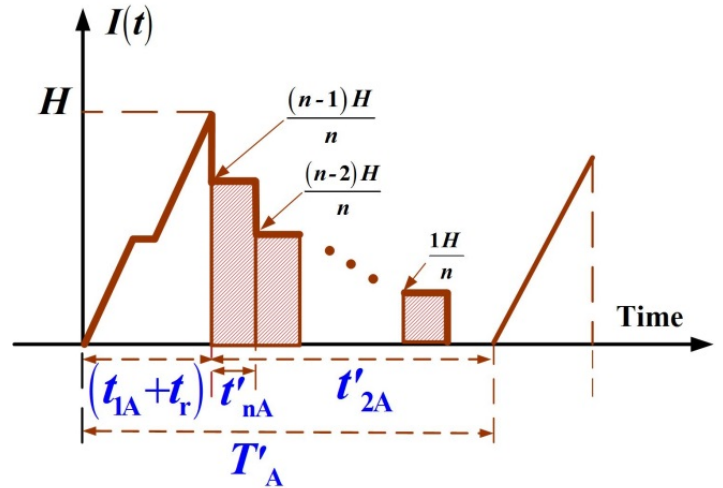

Fig. 4. The finished product level in issuing time in case 1

The buyer product level in case 1 is exhibited in Fig. 5. Total stocks in $T_{\mathrm{A}}^{\prime}$ can be gained as exhibited in Eq. (11).

$$
\frac{n(n-1)}{2} I\left(t^{\prime}{ }_{n \mathrm{~A}}\right)+n\left(t^{\prime}{ }_{n \mathrm{~A}}\right)\left(D-\frac{\lambda\left(t^{\prime}{ }_{n \mathrm{~A}}\right)}{2}\right)+\frac{n I}{2}\left(t_{1 \mathrm{~A}}\right)=\frac{1}{2}\left[T^{\prime}{ }_{\mathrm{A}}\left(H-\lambda t^{\prime}{ }_{2 \mathrm{~A}}\right)+\frac{H t^{\prime}{ }_{2 \mathrm{~A}}}{n}\right]
$$

where

$$
\begin{aligned}
& t^{\prime}{ }_{n \mathrm{~A}}=\frac{t_{2 \mathrm{~A}}^{\prime}}{n} \\
& I=D-\left(\lambda t^{\prime}{ }_{n \mathrm{~A}}\right) \\
& D=\frac{H}{n}
\end{aligned}
$$

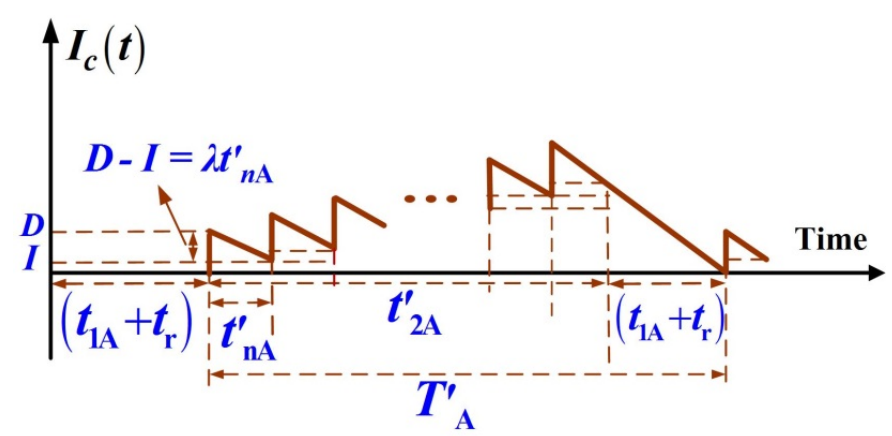

Fig. 5. Buyer product level in case 1 of this problem

In case 1 , the $T C\left(t_{1 \mathrm{~A}}\right)_{1}$ contains the variable and fixed overtime production costs, equipment repair cost, safety product relevant costs, disposal cost, fixed and variable discontinuous product issuing costs, and the sum of the holding costs (including the client's stocks, and the finished and scrap products in $T^{\prime}{ }_{\mathrm{A}}$ ) as follows: 


$$
\begin{aligned}
T C\left(t_{1 \mathrm{~A}}\right)_{1} & =C_{\mathrm{A}} Q+K_{\mathrm{A}}+M+h_{3}\left(\lambda t_{r}\right)\left(t_{1 \mathrm{~A}}+t_{r}\right)+C_{1} \lambda t_{r}+C_{\mathrm{S}} x Q \\
& +n K_{1}+C_{T}\left[Q(1-x)+\lambda t_{r}\right]+\frac{h_{2}}{2}\left[T^{\prime}{ }_{\mathrm{A}}\left(H-\lambda t^{\prime}{ }_{2 \mathrm{~A}}\right)+\frac{H t^{\prime}{ }_{2 \mathrm{~A}}}{n}\right] \\
& +h\left[\left(H_{0} t_{r}\right)+\left(d_{1 \mathrm{~A}} t\right) t_{r}+\frac{\left(H-\lambda t_{r}\right)+d_{1 \mathrm{~A}} t_{1 \mathrm{~A}}}{2}\left(t_{1 \mathrm{~A}}\right)+\left(\frac{n-1}{2 n}\right) H t^{\prime}{ }_{2 \mathrm{~A}}\right]
\end{aligned}
$$

The randomness of $x$ is handled by using the expected values. Substitute equations (1) to (14) in Eq. (15), the following exp ected $E\left[T C\left(t_{1 \mathrm{~A}}\right)_{1}\right]$ can be gained:

$$
\begin{aligned}
& E\left[T C\left(t_{1 \mathrm{~A}}\right)_{1}\right]=\left[\left(1+\alpha_{1}\right) P_{1} t_{1 \mathrm{~A}}\right] C\left(1+\alpha_{3}\right)+K\left(1+\alpha_{2}\right)+C_{T}\left[\left(1+\alpha_{1}\right) P_{1} t_{1 \mathrm{~A}} y_{0}+\lambda g\right] \\
& \quad+n K_{1}+C_{S} P_{1} t_{1 \mathrm{~A}}\left(1+\alpha_{1}\right) E[x]+M+C_{1} \lambda g+\left(h_{2}-h\right) \frac{\left[\left(1+\alpha_{1}\right) P_{1} t_{1 \mathrm{~A}}\right]^{2}}{2 n \lambda} y_{0}\left(y_{0}-y_{1}\right) \\
& \quad+h_{2}\left(\frac{y_{1}}{\lambda}\right) \frac{\left[\left(1+\alpha_{1}\right) P_{1} t_{1 \mathrm{~A}}\right]^{2} y_{0}}{2}+h\left[y_{0}{ }^{2}+E[x] y_{1}\right] \frac{\left[\left(1+\alpha_{1}\right) P_{1} t_{1 \mathrm{~A}}\right]^{2}}{2 \lambda} \\
& +\left(h_{2}-h\right) \frac{g\left(1+\alpha_{1}\right) P_{1} t_{1 \mathrm{~A}}\left(y_{0}-y_{1}\right)}{2 n}+\frac{h_{2} g}{2}\left[\left(1+\alpha_{1}\right) P_{1} t_{1 \mathrm{~A}}\left(y_{0}+y_{1}\right)+\lambda g\right] \\
& +h g\left(1+\alpha_{1}\right)\left[P_{1} t+\frac{P_{1} t_{1 \mathrm{~A}}}{2}\left(y_{0}-y_{1}\right)\right]+h_{3} g\left[\left(1+\alpha_{1}\right) P_{1} t_{1 \mathrm{~A}} y_{1}+\lambda g\right]
\end{aligned}
$$

where

$$
y_{0}=[1-E[x]] ; y_{1}=\left[\frac{\lambda}{\left(1+\alpha_{1}\right) P_{1}}\right] \text {. }
$$

\subsection{Case 2: No random breakdowns happen (i.e., $t \geq t_{1 A}$ )}

The finished product level in case 2 is depicted in Fig. 6. The product level reaches $H$ when uptime ends, and it depletes discontinuously in $t_{2 \mathrm{~A}}$.

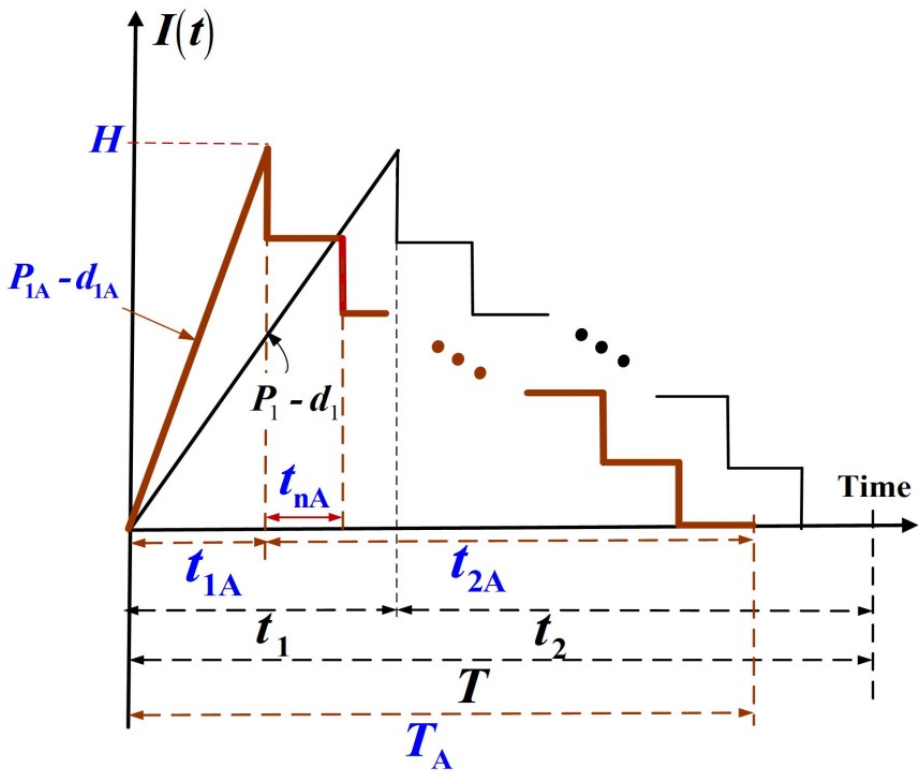

Fig. 6. The finished product level in case 2 of the proposed problem with scrap, and overtime option (in brown) compared to the same problem with scrap only (black)

The safety product level in case 2 is depicted in Fig. 7. Due to no breakdowns happen, $\lambda t_{\mathrm{r}}$ remains unchanged/unused $T_{\mathrm{A}}$. 


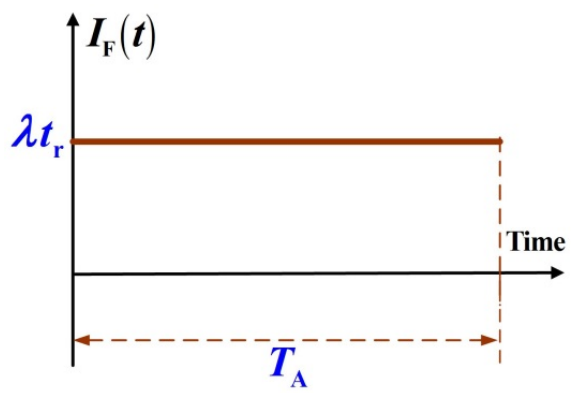

Fig. 7. The safety product level in case 2 of the proposed problem

The maximal scrap product level is $d_{1 \mathrm{~A}} t_{1 \mathrm{~A}}$ when uptime $t_{1 \mathrm{~A}}$ ends (refer to Fig. 3 except that the following variables are utilized: $t_{2 \mathrm{~A}}$ and $T_{\mathrm{A}}$ ). Based on the problem's description and observation of Fig. 6 and Fig. 7, the following formulas are gained:

$$
\begin{aligned}
& t_{1 \mathrm{~A}}=\frac{H_{1}}{P_{1 \mathrm{~A}}-d_{1 \mathrm{~A}}}=\frac{Q}{P_{1 \mathrm{~A}}} \\
& T_{\mathrm{A}}=t_{1 \mathrm{~A}}+t_{2 \mathrm{~A}}=\frac{(1-x) Q}{\lambda} \\
& t_{2 \mathrm{~A}}=T_{\mathrm{A}}-t_{1 \mathrm{~A}}=Q\left[\frac{(1-x)}{\lambda}-\frac{1}{P_{1 \mathrm{~A}}}\right] \\
& H=t_{1 \mathrm{~A}}\left(P_{1 \mathrm{~A}}-d_{1 \mathrm{~A}}\right)
\end{aligned}
$$

In case 2, for the finished product level in $t_{2 \mathrm{~A}}$, please refer to Fig. 4 by replacing the following variables $t_{2 \mathrm{~A}}, t_{\mathrm{nA}}$, and $T_{\mathrm{A}}$. Total inventories in $t_{2 \mathrm{~A}}$ can be computed as follows:

$$
\left(\sum_{i=1}^{n-1} i\right) H\left(t_{2 \mathrm{~A}}\right)\left(\frac{1}{n^{2}}\right)=H\left(t_{2 \mathrm{~A}}\right)\left(\frac{n-1}{2 n}\right)
$$

In case 2 , for the buyer products, please refer to Fig. 6 by replacing the following parameters: $t_{2 \mathrm{~A}}, t_{\mathrm{nA}}$, and $T_{\mathrm{A}}$. Total inventories in $T_{\mathrm{A}}$ can be calculated as follows:

$$
\frac{1}{2}\left[T_{\mathrm{A}}\left(H-\lambda t_{2 \mathrm{~A}}\right)+\frac{H t_{2 \mathrm{~A}}}{n}\right]
$$

In case $2, T C\left(t_{1 \mathrm{~A}}\right)_{2}$ consists of the fixed and variable overtime manufacturing costs, safety items' holding costs, disposal cos $\mathrm{t}$, variable and fixed product issuing costs, and the sum of the holding costs (including the products at the buyer side and the scrap and finished products in $T_{\mathrm{A}}$ ) as follows:

$$
\begin{aligned}
& T C\left(t_{1 \mathrm{~A}}\right)_{2}=Q C_{\mathrm{A}}+K_{\mathrm{A}}+C_{\mathrm{S}} x Q+h_{3}\left(\lambda t_{r}\right) T_{\mathrm{A}}+n K_{1}+C_{T}[Q(1-x)] \\
& \quad+\frac{h_{2}}{2}\left[\frac{H t_{2 \mathrm{~A}}}{n}+\left(H-\lambda t_{2 \mathrm{~A}}\right) T_{\mathrm{A}}\right]+h\left[\frac{H+d_{1 \mathrm{~A}} t_{1 \mathrm{~A}}}{2}\left(t_{1 \mathrm{~A}}\right)+\left(\frac{n-1}{2 n}\right) H t_{2 \mathrm{~A}}\right] .
\end{aligned}
$$

Again, applying $E[x]$ and substitute Eq. (17) to Eq. (22) in Eq. (23), the following $E\left[T C\left(t_{1 \mathrm{~A}}\right)_{2}\right]$ could be gained:

$$
\begin{gathered}
E\left[T C\left(t_{1 \mathrm{~A}}\right)_{2}\right]=C\left(1+\alpha_{3}\right) P_{1} t_{1 \mathrm{~A}}\left(1+\alpha_{1}\right)+K\left(1+\alpha_{2}\right)+C_{S} E[x] P_{1} t_{1 \mathrm{~A}}\left(1+\alpha_{1}\right)+n K_{1} \\
+\left(1+\alpha_{1}\right) C_{T} P_{1} t_{1 \mathrm{~A}} y_{0}+\left(1+\alpha_{1}\right) h_{3} g P_{1} t_{1 \mathrm{~A}} y_{0}+\left(h_{2}-h\right) \frac{\left[\left(1+\alpha_{1}\right) P_{1} t_{1 \mathrm{~A}}\right]^{2} y_{0}\left(y_{0}-y_{1}\right)}{2 n \lambda} \\
+h_{2}\left(\frac{y_{1}}{\lambda}\right) \frac{\left[\left(1+\alpha_{1}\right) P_{1} t_{1 \mathrm{~A}}\right]^{2} y_{0}}{2}+h\left[y_{0}{ }^{2}+E[x] y_{1}\right] \frac{\left[\left(1+\alpha_{1}\right) P_{1} t_{1 \mathrm{~A}}\right]^{2}}{2 \lambda}
\end{gathered}
$$

where 


$$
y_{0}=[1-E[x]] ; y_{1}=\left[\frac{\lambda}{\left(1+\alpha_{1}\right) P_{1}}\right] \text {. }
$$

\section{Solution Procedure}

The time to random machine failure $t$ follows the Exponential distribution because of the assumption of Poisson-distribution breakdown rate of $\beta$, and the cumulative density function and density function of $t$ is $\left(1-e^{-\beta t 1 \mathrm{~A}}\right)$ and $\beta e^{-\beta t 1 \mathrm{~A}}$, respectively. Also, since we have the random scrap rate, so the cycle time varies. Thus, we could apply the renewal reward theorem to coping with variable cycle length. Therefore, $E\left[T C U\left(t_{1 \mathrm{~A}}\right)\right]$ becomes:

$$
E\left[T C U\left(t_{1 \mathrm{~A}}\right)\right]=\frac{\int_{0}^{t_{1 \mathrm{~A}}} E\left[T C\left(t_{1 \mathrm{~A}}\right)_{1}\right] f(t) d t+\int_{t_{1 \mathrm{~A}}}^{\infty} E\left[T C\left(t_{1 \mathrm{~A}}\right)_{2}\right] f(t) d t}{E\left[\boldsymbol{T}_{\mathrm{A}}\right]}
$$

where $E\left[\boldsymbol{T}_{\mathrm{A}}\right], E\left[T^{\prime}{ }_{\mathrm{A}}\right]$, and $E\left[T_{\mathrm{A}}\right]$ represent the following:

$$
\begin{aligned}
E\left[\boldsymbol{T}_{\mathrm{A}}\right] & =\int_{0}^{t_{\mathrm{A}}} E\left[T^{\prime}{ }_{\mathrm{A}}\right] f(t) d t+\int_{t_{1 \mathrm{~A}}}^{\infty} E\left[T_{\mathrm{A}}\right] f(t) d t \\
E\left[T^{\prime}{ }_{\mathrm{A}}\right] & =\frac{Q[1-E[x]]+\lambda t_{r}}{\lambda}=\frac{t_{1 \mathrm{~A}} P_{1 \mathrm{~A}}[1-E[x]]+\lambda t_{r}}{\lambda} \\
E\left[T_{\mathrm{A}}\right] & =\frac{Q[1-E[x]]}{\lambda}=\frac{t_{\mathrm{A}} P_{1 \mathrm{~A}}[1-E[x]]}{\lambda}
\end{aligned}
$$

Substitute Eq. (16), Eq. (24), and Eq. (26) in Eq. (25), along with some derivation efforts we gain $E\left[T C U\left(t_{1 \mathrm{~A}}\right)\right]$ as follows (see Appendix B for details):

$$
E\left[T C U\left(t_{1 \mathrm{~A}}\right)\right]=\frac{\lambda\left(\frac{r_{0}}{t_{1 A}}+\frac{r_{1}}{t_{1 A}}+r_{2} e^{-\beta t_{1 A}}+\frac{r_{3}}{t_{1 A}} e^{-\beta t_{1 A}}-r_{4} e^{-\beta t_{1 A}}+r_{4}+r_{5} t_{1 \mathrm{~A}}+r_{6}\right)}{y_{0}+\frac{\lambda g\left(1-e^{-\beta t_{1 \mathrm{~A}}}\right)}{\left(t_{1 \mathrm{~A}}\right)\left(1+\alpha_{1}\right) P_{1}}}
$$

\subsection{Convexity of $E\left[T C U\left(t_{1 A}\right)\right]$}

We now calculate the first- and second-derivatives of $E\left[T C U\left(t_{1 \mathrm{~A}}\right)\right]$ (see Eqs. $(\mathrm{C}-1)$ and $(\mathrm{C}-2)$ in Appendix $\mathrm{C}$ for the detailed results). The first term on the right-hand side (RHS) of formula (C-2) is positive; hence, if the second term of the RHS of Eq. $(\mathrm{C}-2)$ is also positive, then $E\left[T C U\left(t_{1 \mathrm{~A}}\right)\right]$ is convex, i.e., if $\omega\left(t_{1 \mathrm{~A}}\right)>t_{1 \mathrm{~A}}>0$ holds (see Eq. (C-3)). Upon verification of Eq. (B3 ), the optimal $t_{1 \mathrm{~A}} *$ can be derived by letting the first-derivative of $E\left[T C U\left(t_{1 \mathrm{~A}}\right)\right]=0$ (see Eq. (C-1)). Since the first term on the RHS of Eq. (C-1) is positive, one has the following:

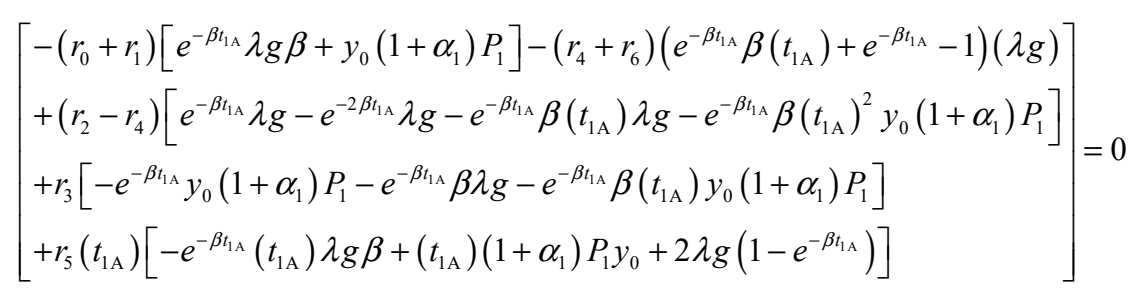

Let $\delta_{0}, \delta_{1}$, and $\delta_{2}$ be the following:

$$
\begin{aligned}
& \delta_{0}=\left(r_{2}-r_{4}\right)\left[-e^{-\beta t_{1} \wedge} \beta y_{0}\left(1+\alpha_{1}\right) P_{1}\right]+r_{5}\left[-e^{-\beta t_{1}} \lambda g \beta+\left(1+\alpha_{1}\right) P_{1} y_{0}\right] \\
& \delta_{1}=r_{5}\left(1-e^{-\beta t_{1 \wedge}}\right) 2 \lambda g-\left(e^{-\beta t_{1 \wedge}} \beta\right)\left[\left(r_{2}-r_{4}\right)(\lambda g)+\left(r_{4}+r_{6}\right)(\lambda g)+r_{3} y_{0}\left(1+\alpha_{1}\right) P_{1}\right] \\
& \delta_{2}=\left[\begin{array}{l}
-\left(r_{0}+r_{1}\right)\left[e^{-\beta t_{1}} \lambda g \beta+y_{0}\left(1+\alpha_{1}\right) P_{1}\right]-\left(r_{4}+r_{6}\right)\left(e^{-\beta t_{\mathrm{A}}}-1\right)(\lambda g) \\
-r_{3} e^{-\beta t_{1}}\left[y_{0}\left(1+\alpha_{1}\right) P_{1}+\beta \lambda g\right]+\left(r_{2}-r_{4}\right)\left(e^{-\beta t_{1 \mathrm{~A}}}-e^{-2 \beta t_{\mathrm{A}}}\right) \lambda g
\end{array}\right]
\end{aligned}
$$

Then, Eq. (28) becomes:

$$
\delta_{0}\left(t_{1 \mathrm{~A}}\right)^{2}+\delta_{1}\left(t_{1 \mathrm{~A}}\right)+\delta_{2}=0
$$

The following $t_{\mathrm{A}} *$ can be derived using the square root solution: 


$$
t_{1 \mathrm{~A}}{ }^{*}=\frac{-\delta_{1} \pm \sqrt{\delta_{1}^{2}-4 \delta_{0} \delta_{2}}}{2 \delta_{0}}
$$

\subsection{Searching algorithm for $t_{1 A} *$}

As the function $F\left(t_{1 \mathrm{~A}}\right)=\left(1-e^{-\beta t 1 \mathrm{~A}}\right)$ is over $[0,1]$ interval, so does $e^{-\beta t 1 \mathrm{~A}}$. Moreover, we can rearrange Eq. (30) as follows:

$$
e^{-\beta t_{1 \mathrm{~A}}}=\frac{-\left(r_{0}+r_{1}\right) P_{1}\left(1+\alpha_{1}\right) y_{0}+\left(r_{4}+r_{6}\right)(\lambda g)+r_{5} t_{1 \mathrm{~A}}\left[2 \lambda g+P_{1} y_{0} t_{1 \mathrm{~A}}\left(1+\alpha_{1}\right)\right]}{\left\{\begin{array}{l}
\left(r_{0}+r_{1}\right) \beta \lambda g+\left(r_{4}+r_{6}\right)\left(\beta t_{1 \mathrm{~A}}+1\right) \lambda g+r_{3}\left[\left(1+\alpha_{1}\right) y_{0} P_{1}\left(1+\beta t_{1 \mathrm{~A}}\right)+\beta \lambda g\right] \\
+\left(r_{2}-r_{4}\right)\left[\left(\beta t_{1 \mathrm{~A}}+e^{-\beta t_{\mathrm{A}}}-1\right) \lambda g+P_{1}\left(1+\alpha_{1}\right) \beta t_{1 \mathrm{~A}}^{2} y_{0}\right]+r_{5}\left(2+t_{1 \mathrm{~A}} \beta\right) \lambda g t_{1 \mathrm{~A}}
\end{array}\right\}}
$$

This study proposed the following optimal $t_{1 \mathrm{~A}} *$ searching algorithm:

Step-1: $\quad$ Set $e^{-\beta t 1 \mathrm{~A}}=1$ and $e^{-\beta t 1 \mathrm{~A}}=0$, and apply Eq. (30) to obtain initial bounds $t_{1 \mathrm{AU}}$ and $t_{1 \mathrm{AL}}$.

Step-2: Use the present $t_{1 \mathrm{AU}}$ and $t_{1 \mathrm{AL}}$ to obtain/update $e^{-\beta t 1 \mathrm{AU}}$ and $e^{-\beta t 1 \mathrm{AL}}$.

Step-3: Apply Eq. (30) again with the present $e^{-\beta t 1 \mathrm{AU}}$ and $e^{-\beta t 1 \mathrm{AL}}$ to compute the updated bounds $t_{1 \mathrm{AU}}$ and $t_{1 \mathrm{AL}}$.

Step-4: If current $t_{1 \mathrm{AU}}=t_{1 \mathrm{AL}}$, then go to Step-5; otherwise, go back to Step-2.

Step-5: Stop, $t_{1 \mathrm{~A}} *$ is derived (i.e., $t_{1 \mathrm{~A}} *=t_{1 \mathrm{AU}}=t_{1 \mathrm{AL}}$ ).

\section{Numerical Demonstration}

This section offers a numerical demonstration to show how our model works. First, Table 1 gives the assumed values of all relevant system variables in this example.

Table 1

The assumed values of all relevant system variables in this example

\begin{tabular}{ccccccccccccc}
\hline Variables & $\lambda$ & $C_{\mathrm{A}}$ & $P_{1 \mathrm{~A}}$ & $\beta$ & $\mathrm{M}$ & $K_{\mathrm{A}}$ & $C_{\mathrm{S}}$ & $C_{\mathrm{T}}$ & $K_{1}$ & $\alpha_{1}$ & $\alpha_{3}$ \\
\hline & 4000 & 2.5 & 15000 & 1 & 2500 & 220 & 0.1 & 0.01 & 90 & 0.5 & 0.25 \\
& $x$ & $C$ & $P_{1}$ & $h$ & $g$ & $K$ & $h_{2}$ & $C_{1}$ & $n$ & $\alpha_{2}$ & $h_{3}$ & \\
& $20 \%$ & 2.0 & 10000 & 0.4 & 0.018 & 200 & 1.6 & 2.0 & 3 & 0.1 & 0.4 & \\
\hline
\end{tabular}

As stated in previous section, before solving the problem we have to confirm the convexity of cost function first, that is to make sure that $\omega\left(t_{1 \mathrm{~A}}\right)>t_{1 \mathrm{~A}}>0$ (Eq. (C-3)) holds. Since $e^{-\beta t 1 \mathrm{~A}}$ falls within $[0,1]$, let $e^{-\beta t 1 \mathrm{~A}}=0$ and $e^{-\beta t 1 \mathrm{~A}}=1$, and apply Eq. (30) to find obtain $t_{1 \mathrm{AU}}=0.3326$ and $t_{1 \mathrm{AL}}=0.0958$, respectively; then using the obtained $t_{1 \mathrm{AU}}$ and $t_{1 \mathrm{AL}}$ to calculate $e^{-\beta t 1 \mathrm{AU}}=$ 0.7170 and $e^{-\beta t 1 \mathrm{AL}}=0.9087$. Lastly, apply Eq. $(\mathrm{C}-3)$ to gain $\omega\left(t_{1 \mathrm{AL}}\right)=0.2984>t_{1 \mathrm{AL}}=0.0958>0$ and $\omega\left(t_{1 \mathrm{AU}}\right)=0.5646>t_{1 \mathrm{AU}}$ $=0.3326>0$, respectively. Hence, the convexity of $E\left[T C U\left(t_{1 \mathrm{~A}}\right)\right]$ is confirmed for $\beta=1$ and the minimal value of the cost function of the given example exists. To show that our proposed model can be broadly applied, extra convexity tests were performed using broader values of $\beta$ (Table 2 exhibits the outcomes).

Table 2

The outcomes of extra convexity tests with a broader values of $\beta$

\begin{tabular}{ccccc}
\hline$\beta$ & $\omega\left(t_{1 \mathrm{AL}}\right)$ & $t_{1 \mathrm{AL}}$ & $\omega\left(t_{1 \mathrm{AU}}\right)$ & $t_{1 \mathrm{AU}}$ \\
\hline 12 & 0.0372 & 0.0174 & 1.6096 & 0.3271 \\
9 & 0.0484 & 0.0225 & 0.9436 & 0.3273 \\
6 & 0.0702 & 0.0322 & 0.6171 & 0.3276 \\
5 & 0.0826 & 0.0375 & 0.5543 & 0.3278 \\
4 & 0.1006 & 0.0449 & 0.5100 & 0.3281 \\
3 & 0.1285 & 0.0554 & 0.4851 & 0.3286 \\
2 & 0.1780 & 0.0712 & 0.4879 & 0.3296 \\
$\mathbf{1}$ & $\mathbf{0 . 2 9 8 4}$ & $\mathbf{0 . 0 9 5 8}$ & $\mathbf{0 . 5 6 4 6}$ & $\mathbf{0 . 3 3 2 6}$ \\
0.5 & 0.4926 & 0.1128 & 0.7403 & 0.3386 \\
\hline .01 & 3.8353 & 0.1332 & 4.4254 & 0.7129 \\
\hline
\end{tabular}

To locate $t_{1 \mathrm{~A}}{ }^{*}$, we proposed the following searching algorithm (refer to subsection 3.2):

Step-1: $\quad$ Set $e^{-\beta t 1 \mathrm{~A}}=0$ and $e^{-\beta t 1 \mathrm{~A}}=1$, and apply Eq. (30) to obtain initial bounds $t_{1 \mathrm{AU}}=0.3326$ and $t_{1 \mathrm{AL}}=0.0958$, respectively.

Step-2: Use the present $t_{1 \mathrm{AU}}$ and $t_{1 \mathrm{AL}}$ to obtain $e^{-\beta t 1 \mathrm{AU}}=0.7170$ and $e^{-\beta t 1 \mathrm{AL}}=0.9087$, respectively.

Step-3: Apply Eq. (30) with the present $e^{-\beta t 1 \mathrm{AU}}$ and $e^{-\beta t 1 \mathrm{AL}}$ to gain the new bounds for $t_{1 \mathrm{AU}}=0.1798$ and $t_{1 \mathrm{AL}}=0.1261$, respectively. 
Step-4: If the current $t_{1 \mathrm{AU}}=t_{1 \mathrm{AL}}$, then go to Step-5; otherwise, go back to Step-2 (see Table 3 for the detailed results from this recursive algorithm).

Step-5: Stop, $t_{1 \mathrm{~A}} *$ is derived (i.e., $\left.t_{1 \mathrm{~A}} *=t_{1 \mathrm{AU}}=t_{1 \mathrm{AL}}=0.1374\right)$.

Table 3 gives the details of the proposed $t_{1 \mathrm{~A}} *$ seeking processes and specifies the resulting $t_{1 \mathrm{~A}} *=0.1374$, and by applying Eq. (27), we obtain $E\left[T C U\left(t_{1 \mathrm{~A}} *\right)\right]=\$ 14,017.88$ for this example. The advance analysis exposes the behavior of $E\left[T C U\left(t_{1 \mathrm{~A}}\right)\right]$ concerning $t_{1 \mathrm{~A}}$ (refer to Fig. 8). It shows the initial positions of bounds $t_{1 \mathrm{AL}}$ and $t_{1 \mathrm{AU}}$, and also points out how $E\left[T C U\left(t_{1 \mathrm{~A}}\right)\right]$ knowingly increases as $t_{1 \mathrm{~A}}$ departs from $t_{1 \mathrm{~A}} *$ (i.e., 0.1374 ).

Table 3

The detailed results from applying the proposed searching e algorithm for $t_{1 \mathrm{~A}}$ *

\begin{tabular}{cccccccc}
\hline Step \# & $t_{1 \mathrm{AL}}$ & $e^{-\beta t 1 \mathrm{AL}}$ & $t_{1 \mathrm{AU}}$ & $e^{-\beta t 1 \mathrm{AU}}$ & {$\left[t_{1 \mathrm{AU}}-t_{1 \mathrm{AL}}\right]$} & $E\left[T C U\left(t_{1 \mathrm{AL}}\right)\right]$ & $E\left[T C U\left(t_{1 \mathrm{AU}}\right)\right]$ \\
\hline- & - & 1 & - & 0 & - & - & - \\
1 & $\mathbf{0 . 0 9 5 8}$ & 0.9087 & $\mathbf{0 . 3 3 2 6}$ & 0.7170 & 0.2368 & $\$ 14,156.18$ & $\$ 14,897.25$ \\
2 & 0.1261 & 0.8815 & 0.1798 & 0.8354 & 0.0537 & $\$ 14,025.54$ & $\$ 14,094.67$ \\
3 & 0.1344 & 0.8742 & 0.1479 & 0.8625 & 0.0135 & $\$ 14,018.37$ & $\$ 14,023.62$ \\
4 & 0.1366 & 0.8723 & 0.1401 & 0.8693 & 0.0035 & $\$ 14,017.92$ & $\$ 14,018.28$ \\
5 & 0.1372 & 0.8718 & 0.1381 & 0.8710 & 0.0009 & $\$ 14,017.89$ & $\$ 14,017.91$ \\
6 & 0.1373 & 0.8717 & 0.1376 & 0.8715 & 0.0003 & $\$ 14,017.88$ & $\$ 14,017.89$ \\
7 & 0.1373 & 0.8717 & 0.1374 & 0.8716 & 0.0001 & $\$ 14,017.88$ & $\$ 14,017.88$ \\
8 & $\mathbf{0 . 1 3 7 4}$ & 0.8716 & $\mathbf{0 . 1 3 7 4}$ & 0.8716 & 0.0000 & $\mathbf{\$ 1 4 , 0 1 7 . 8 8}$ & $\mathbf{\$ 1 4 , 0 1 7 . 8 8}$ \\
\hline
\end{tabular}

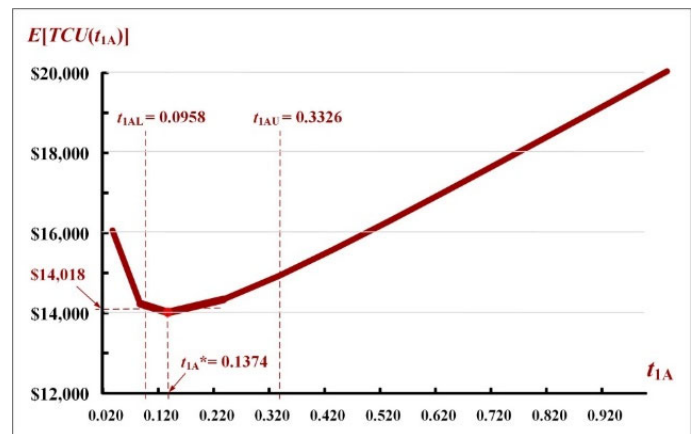

Fig. 8. Behavior of $E\left[T C U\left(t_{1 \mathrm{~A}}\right)\right]$ relating to $t_{1 \mathrm{~A}}$

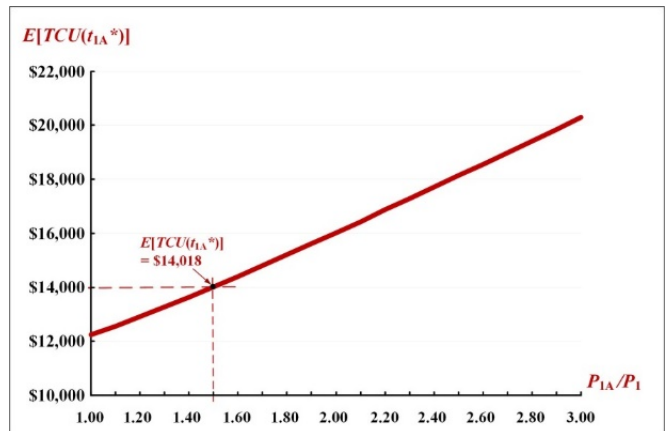

Fig. 9. Impact of differences in the overtime ratio $P_{1 \mathrm{~A}} / P_{1}$ on $E\left[T C U\left(t_{1 \mathrm{~A}}^{*}\right)\right]$

Fig. 9 discloses the impact of variations in $P_{1 \mathrm{~A}} / P_{1}$ on $E\left[T C U\left(t_{1 \mathrm{~A}} *\right)\right]$. It specifies $E\left[T C U\left(t_{1 \mathrm{~A}} *\right)\right]$ rises significantly as $P_{1 \mathrm{~A}} / P_{1}$ increases, and it reconfirms the optimal cost $E\left[T C U\left(t_{1 \mathrm{~A}} *\right)\right]=\$ 14,018$ at $P_{1 \mathrm{~A}} / P_{1}=1.5$ in our example. The behavior of utilization concerning the overtime ratio $P_{1 \mathrm{~A}} / P_{1}$ is illustrated in Fig. 10. It exposes that the utilization declines noticeably, as $P_{1 \mathrm{~A}} / P_{1}$ increases; notably, it drops from $44.12 \%$ to $29.48 \%$, as the $P_{1 \mathrm{~A}} / P_{1}$ increases from 1.00 to 1.50 (i.e., an extra $50 \%$ more output rate due to the implementation of overtime strategy or $\left.\alpha_{1}=0.5\right)$. Fig. 11 discovers the effect of changes in $x$ on key system cost components. It discloses that as scrap rate $x$ increases, the quality relating cost rises radically, and the overtime/expedited fabrication cost rises mildly. The other cost components seem to insignificantly change.

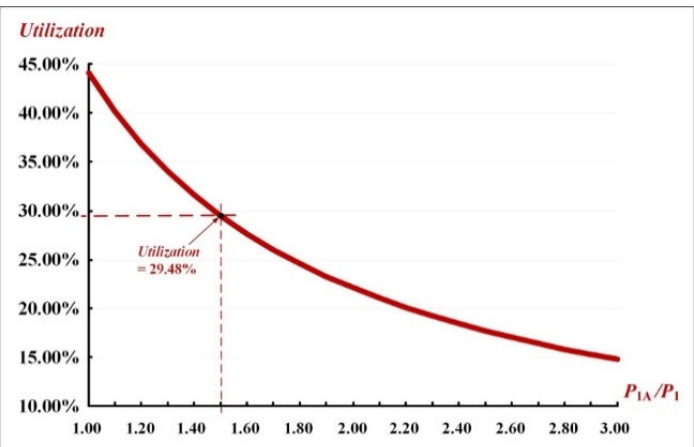

Fig. 10. Behavior of utilization regarding $P_{1 \mathrm{~A}} / P_{1}$

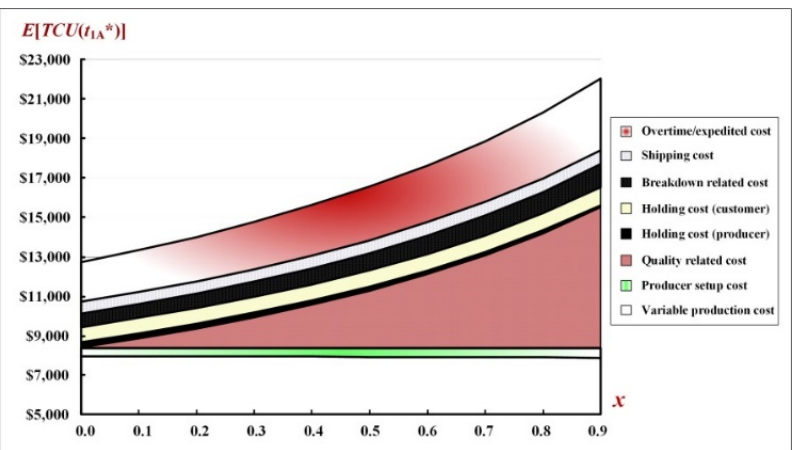

Fig. 11. Effect of differences in $x$ on crucial system cost components 
Fig. 12 shows the effect of variations in $x$ on $t_{1 \mathrm{~A}} *$. It discloses that the $t_{1 \mathrm{~A}}{ }^{*}$ surges notably, as $x$ rises; and $t_{1 \mathrm{~A}} *=0.1374$ is reconfirmed (at $x=0.2$ ) for our example.

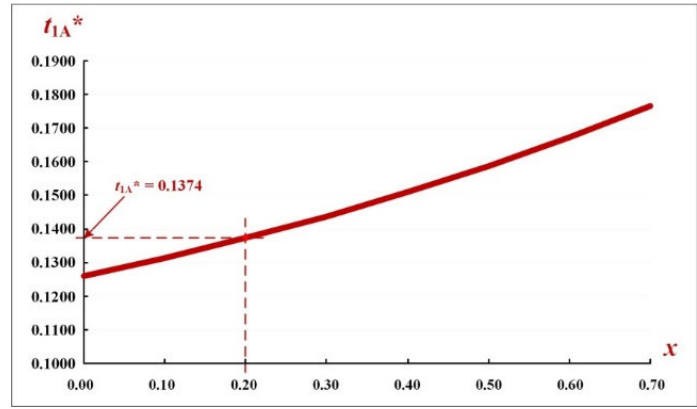

Fig. 12. Effect of variations in $x$ on $t_{1 \mathrm{~A}}{ }^{*}$

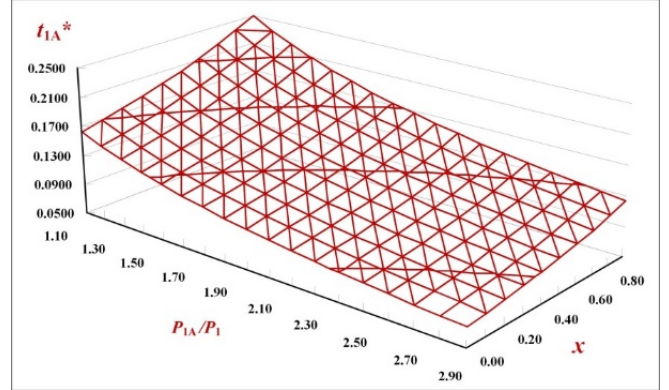

Fig. 13. Collective impact of variations in $P_{1 \mathrm{~A}} / P_{1}$ and $x$ on $t_{1 \mathrm{~A}} *$

The collective impact of changes in the overtime ratio $P_{1 \mathrm{~A}} / P_{1}$ and $x$ on the $t_{1 \mathrm{~A}} *$ is displayed in Fig. 13. It exposes that $t_{1 \mathrm{~A}} *$ decreases considerably, as $P_{1 \mathrm{~A}} / P_{1}$ rises; conversely, $t_{1 \mathrm{~A}} *$ increases noticeably, as $x$ goes up. Fig. 14 displays the impact of variations in $n$ on key system cost components. At $n=1$, it confirms the client's holding cost is relatively high; conversely, the producer's holding cost is considerably low. Generally, as $n$ increase, the system's shipping cost boosts significantly, and the producer's holding cost rises noticeably, the latter is due to the slow stock movement from producer to customer.

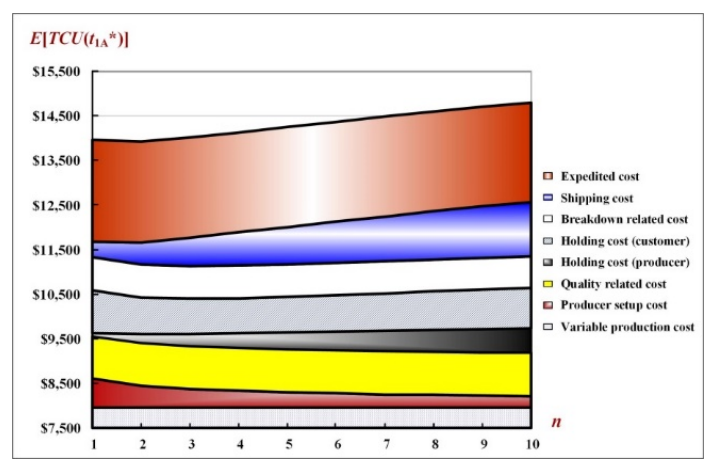

Fig. 14. The impact of changes in $n$ on crucial cost components of the system

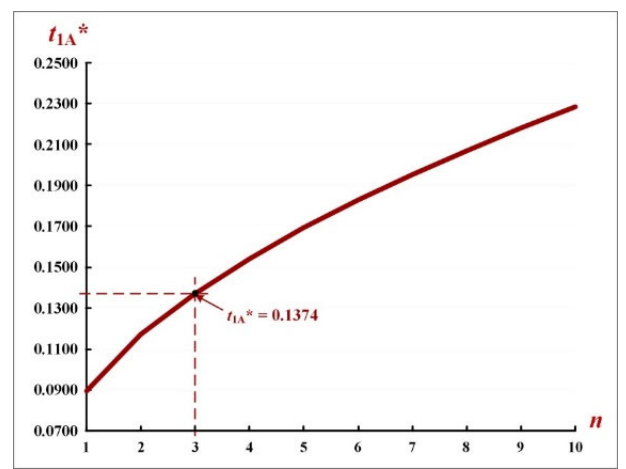

Fig. 15. Behavior of $t_{1 \mathrm{~A}}$ * concerning $n$

The behavior of $t_{1 \mathrm{~A}} *$ concerning the frequency of shipping $n$ is illustrated in Fig. 15. It reveals that $t_{1 \mathrm{~A}} *$ upsurges radically, as $n$ increases, and it reconfirms that at $n=3, t_{1 \mathrm{~A}} *=0.1374$ in the example. Fig. 16 depicts the influence of variations in $1 / \beta$ with varied $x$ values on $E\left[T C U\left(t_{1 \mathrm{~A}}{ }^{*}\right)\right]$. It shows that as $1 / \beta$ increases (i.e., the occurrences of breakdown decrease), $E\left[T C U\left(t_{1 \mathrm{~A}} *\right)\right]$ declines significantly. Especially, beginning from $1 / \beta>0.25, E\left[\operatorname{TCU}\left(t_{1 \mathrm{~A}} *\right)\right]$ severely declines. As $1 / \beta$ reaches infinite (i.e., no failure instance during fabrication) the system cost increases to $\$ 13,343$ as. Fig. 16 also reconfirms our solution: $E\left[T C U\left(t_{1 \mathrm{~A}}{ }^{*}\right)\right]=\$ 14,018$ at $1 / \beta=1$.

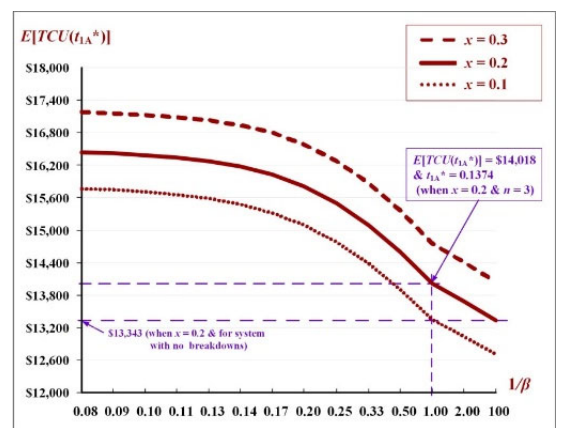

Fig. 16. Influence of variations in $1 / \beta$ with different scrap rates $x$ on $E\left[T C U\left(t_{1 \mathrm{~A}}{ }^{*}\right)\right]$

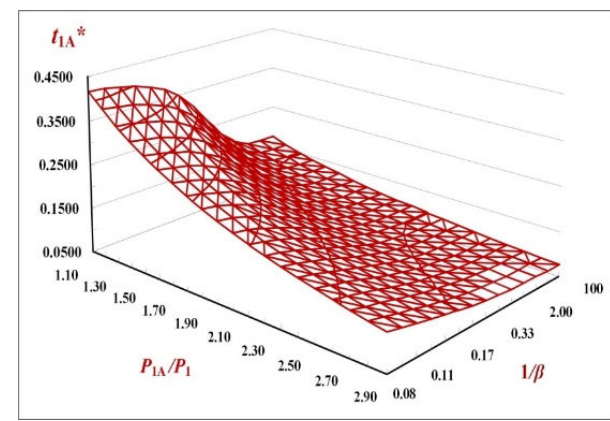

Fig. 17. The collective impact of differences in $P_{1 \mathrm{~A}} / P_{1}$ and $1 / \beta$ on $t_{1 \mathrm{~A}}{ }^{*}$

Fig. 17 exhibits the collective impact of differences in $P_{1 \mathrm{~A}} / P_{1}$ and $1 / \beta$ on $t_{1 \mathrm{~A}} *$. It reveals that $t_{1 \mathrm{~A}} *$ decreases significantly, as both the $P_{1 \mathrm{~A}} / P_{1}$ ratio and $1 / \beta$ increase (this confirms that the uptime reduced extensively as the overtime ratio $P_{1 \mathrm{~A}} / P_{1}$ rises). The combined effect of variations in $t_{1 \mathrm{~A}}$ and $x$ on $E\left[T C U\left(t_{1 \mathrm{~A}} *\right)\right]$ is exhibited in Fig. 18. It shows that $E\left[T C U\left(t_{1 \mathrm{~A}}{ }^{*}\right)\right]$ increases drastically, as $x$ rises; and as $t_{1 \mathrm{~A}}$ deviates from its optimal point (i.e., $\left.t_{1 \mathrm{~A}} *=0.1374\right), E\left[T C U\left(t_{1 \mathrm{~A}} *\right)\right]$ increases significantly. 


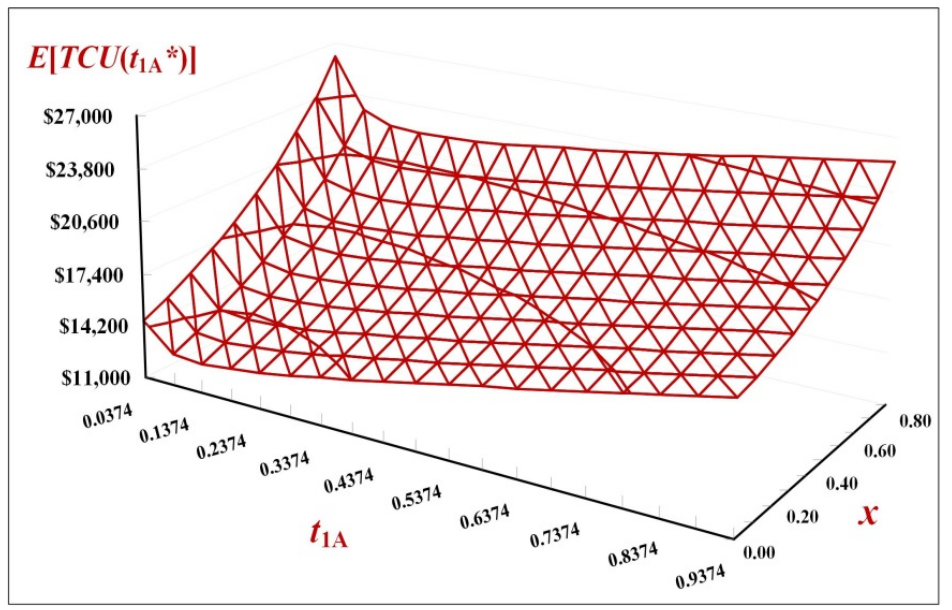

Fig. 18. Combined influence of differences in $t_{1 \mathrm{~A}}$ and $x$ on $E\left[T C U\left(t_{1 \mathrm{~A}}{ }^{*}\right)\right]$

\section{Conclusions}

This research explores the collective impact of scrap, random breakdown, overtime, and discontinuous issuing rule on batch production planning. To accurately represent the situations of the stochastic failure, two separate cases are analyzed (refer to the subsections 2.1 and 2.2) and integrated (see section 3) to derive the expected annual total system cost function. Once we confirm the cost function's convexity, an algorithm is used to help in seeking the fabrication system's optimal runtime (refer to the subsections 3.1 and 3.2, and the section 4 for numerical illustrations). This work contributes to the existing literature in the following areas: (i) It builds a mathematical model and presents a solution process to explore the problem. (ii) It offers a decision support system to enable an in-depth investigation of the collective and individual impacts of scrap, random breakdown, and overtime on the manufacturing runtime decision, diverse cost contributors, utilization, and total costs for this fabrication-transportation- inventory system (refer to Figs. 8-18). (iii) This model and the research findings can facilitate manufacturer's decision-making for green fabrication, and allow them to enhance competitive advantage. To combine the stochastic demand into the same context of this problem is an interesting subject for future study.

\section{Acknowledgment}

The researchers thank the Ministry of Science and Technology of Taiwan for sponsoring this work (project\#: MOST 1082221-E-324-009).

\section{Appendix - A}

Additional notation utilized in this work.

$t_{1 \mathrm{~A}}=$ uptime in the breakdown-happening case,

$t_{2 \mathrm{~A}}^{\prime}=$ product issuing time in the breakdown happening case,

$t_{\mathrm{nA}}^{\prime}=$ the interval of time between two consecutive shipments in the breakdown happening case,

$t_{\mathrm{r}} \quad=$ time needed for breakdown repairing,

$T_{\mathrm{A}}^{\prime}=$ cycle time in the breakdown-happening case,

$Q \quad=$ the lot size,

$\beta=$ Poisson distributed breakdown rate,

$t \quad=$ time to a stochastic breakdown happens,

$M$ = breakdown repair cost,

$x=$ uniformly distributed scrap rate,

$C_{\mathrm{S}}=$ unit disposal cost,

$h=$ unit holding cost,

$C_{1}=$ safety product unit cost,

$h_{3}=$ safety product unit holding cost,

$K_{1}$ = fixed issuing cost,

$C_{\mathrm{T}}=$ unit issuing cost,

$h_{2}=$ buyer product unit holding cost,

$H_{0}$ = finished product level when a random breakdown happens,

$H$ = finished product level when uptime ends,

$t_{2 \mathrm{~A}}=$ finished product issuing time in the no breakdown-happening case,

$t_{\mathrm{nA}}=$ the interval of time between two consecutive shipments in the no breakdown-happening case, 
$T_{\mathrm{A}}=$ cycle time in the no breakdown-happening case,

$t_{1}=$ uptime for a system without breakdown, nor overtime implementation,

$t_{2}=$ product issuing time for a system without breakdown, nor overtime implementation,

$T=$ cycle time for a system without breakdown, nor overtime implementation,

$g \quad=$ fixed failure repair time (i.e., $t_{\mathrm{r}}$ ),

$I(t)=$ finished product level at time $t$,

$I_{\mathrm{F}}(t)=$ safety product level at time $t$,

$I_{\mathrm{s}}(t)=$ scrap product level at time $t$,

$D$ = products per shipment,

$I \quad=$ leftover products after each issuing time,

$I_{\mathrm{c}}(t)=$ buyer product level at time $t$,

$T C\left(t_{1 \mathrm{~A}}\right)_{1}=$ total cost per cycle in the breakdown case,

$E\left[T C\left(t_{1 \mathrm{~A}}\right)_{1}\right]=$ expected total cost per cycle in the breakdown case,

$E\left[T_{\mathrm{A}}^{\prime}\right]=$ expected cycle time in the breakdown case,

$T C\left(t_{1 \mathrm{~A}}\right)_{2}=$ total cost per cycle in the no breakdown case,

$E\left[T C\left(t_{1 \mathrm{~A}}\right)_{2}\right]=$ expected total cost per cycle in the no breakdown case,

$E\left[T_{\mathrm{A}}\right]=$ expected cycle time in the no breakdown case,

$\boldsymbol{T}_{\mathbf{A}}=$ cycle time for a system with/without a breakdown-happening,

$E\left[T C U\left(t_{1 \mathrm{~A}}\right)\right]=$ expected system cost per unit time for a system with/without a breakdown-happening.

\section{Appendix - B}

Derivations of Eq. (27) are as follows: by substituting Eq. (16), Eq. (24), and Eq. (26) in Eq. (25), one gains the following:

$$
\begin{aligned}
& E\left[\operatorname{TCU}\left(t_{1 \mathrm{~A}}\right)\right]=\left[\frac{\lambda}{y_{0}+\frac{\left(1-e^{-\beta t_{1 \mathrm{~A}}}\right) \lambda g}{\left(1+\alpha_{1}\right) P_{1} t_{1 \mathrm{~A}}}}\right] . \\
& {\left[\frac{n K_{1}}{\left(1+\alpha_{1}\right) P_{1}\left(t_{1 \mathrm{~A}}\right)}+\frac{K\left(1+\alpha_{2}\right)}{\left(1+\alpha_{1}\right) P_{1}\left(t_{1 \mathrm{~A}}\right)}+C\left(1+\alpha_{3}\right)+C_{S} E[x]+h_{3}\left(e^{-\beta t_{1 \mathrm{~A}}}\right) g y_{0}\right.} \\
& +C_{T} y_{0}+\left(h_{2}-h\right) \frac{\left(1+\alpha_{1}\right) P_{1}\left(t_{1 \mathrm{~A}}\right) y_{0}\left(y_{0}-y_{1}\right)}{2 n \lambda}+h_{2}\left(\frac{y_{1}}{\lambda}\right) \frac{\left(1+\alpha_{1}\right) P_{1}\left(t_{1 \mathrm{~A}}\right) y_{0}}{2} \\
& +h\left[y_{0}^{2}+E[x] y_{1}\right] \frac{\left(1+\alpha_{1}\right) P_{1}\left(t_{1 \mathrm{~A}}\right)}{2 \lambda}+\frac{\left(1-e^{-\beta t_{1 \mathrm{~A}}}\right) M}{\left[\left(1+\alpha_{1}\right) P_{1}\right]\left(t_{1 \mathrm{~A}}\right)} \\
& +\frac{C_{1}\left(1-e^{-\beta t_{1 \mathrm{~A}}}\right) \lambda g}{\left(1+\alpha_{1}\right) P_{1}\left(t_{1 \mathrm{~A}}\right)}+h\left(-t_{1 \mathrm{~A}} e^{-\beta t_{1 \mathrm{~A}}}-\frac{1}{\beta} e^{-\beta t_{1 \mathrm{~A}}}+\frac{1}{\beta}\right) \frac{g}{t_{1 \mathrm{~A}}}+h_{2} \frac{\left(1-e^{-\beta t_{1 \mathrm{~A}}}\right) \lambda g^{2}}{2\left(1+\alpha_{1}\right) P_{1}\left(t_{1 \mathrm{~A}}\right)} \\
& +\frac{C_{T}\left(1-e^{-\beta t_{1 \mathrm{~A}}}\right) \lambda g}{\left(1+\alpha_{1}\right) P_{1} t_{1 \mathrm{~A}}}+\frac{g}{2}\left(1-e^{-\beta t_{1 \mathrm{~A}}}\right)\left(y_{0}-y_{1}\right)\left[\frac{\left(h_{2}-h\right)}{n}+h\right] \\
& +\frac{\left(1-e^{-\beta t_{1 \mathrm{~A}}}\right)\left(y_{0}+y_{1}\right) g h_{2}}{2}+h_{3}\left(1-e^{-\beta t_{\mathrm{IA}}}\right) g\left[y_{1}+\frac{\lambda g}{\left(t_{1 \mathrm{~A}}\right)\left(1+\alpha_{1}\right) P_{1}}\right]
\end{aligned}
$$

Let $r_{0}, r_{1}, r_{2}, r_{3}, r_{4}, r_{5}$, and $r_{6}$ be the following:

$$
\begin{aligned}
& r_{0}=\frac{n K_{1}+\left(1+\alpha_{2}\right) K}{\left(1+\alpha_{1}\right) P_{1}} \\
& r_{1}=\frac{h_{3} \lambda g^{2}+C_{T} \lambda g+M+C_{1} \lambda g}{\left(1+\alpha_{1}\right) P_{1}}+\frac{h g}{\beta}+\frac{h_{2} \lambda g^{2}}{2\left(1+\alpha_{1}\right) P_{1}} \\
& r_{2}=-h g \\
& r_{3}=-r_{1} \\
& r_{4}=\frac{g}{2}\left[\left(y_{0}-y_{1}\right)\left(h+\frac{\left(h_{2}-h\right)}{n}\right)+\left(y_{0}+y_{1}\right)\left(h_{2}+2 h_{3}\right)\right]
\end{aligned}
$$




$$
\begin{aligned}
& r_{5}=\frac{\left(1+\alpha_{1}\right) P_{1}}{2}\left\{\frac{h_{2} y_{0} y_{1}}{\lambda}+\frac{\left(h_{2}-h\right)\left(y_{0}-y_{1}\right) y_{0}}{n \lambda}+\frac{h}{\lambda}\left[E[x] y_{1}+y_{0}^{2}\right]\right\} \\
& r_{6}=C_{T} y_{0}+C_{S} E[x]+C\left(1+\alpha_{3}\right)
\end{aligned}
$$

and

$$
y_{0}=1-E[x] ; y_{1}=\frac{\lambda}{\left(1+\alpha_{1}\right) P_{1}} \text {. }
$$

Then, Eq. (B-1) becomes the following:

$$
E\left[T C U\left(t_{1 \mathrm{~A}}\right)\right]=\frac{\lambda\left(r_{0} \frac{1}{t_{1 A}}+r_{1} \frac{1}{t_{1 A}}+r_{2} e^{-\beta t_{1 A}}+r_{3} e^{-\beta t_{1 A}} \frac{1}{t_{1 A}}-r_{4} e^{-\beta t_{1 A}}+r_{4}+r_{5} t_{1 \mathrm{~A}}+r_{6}\right)}{y_{0}+\frac{\left(1-e^{-\beta t_{\mathrm{A}}}\right) \lambda g}{\left(1+\alpha_{1}\right) P_{1} t_{1 \mathrm{~A}}}}
$$

\section{Appendix - C}

The following are the first- and second-derivatives of $E\left[T C U\left(t_{1 \mathrm{~A}}\right)\right]$ :

$$
\begin{aligned}
& \frac{d E\left[\operatorname{TCU}\left(t_{1 \mathrm{~A}}\right)\right]}{d\left(t_{1 \mathrm{~A}}\right)}=\frac{\left(1+\alpha_{1}\right) \lambda P_{1}}{\left[\left(1+\alpha_{1}\right)\left(t_{1 \mathrm{~A}}\right) P_{1} y_{0}+\left(1-e^{-\beta t_{\mathrm{A}}}\right) \lambda g\right]^{2}} .
\end{aligned}
$$

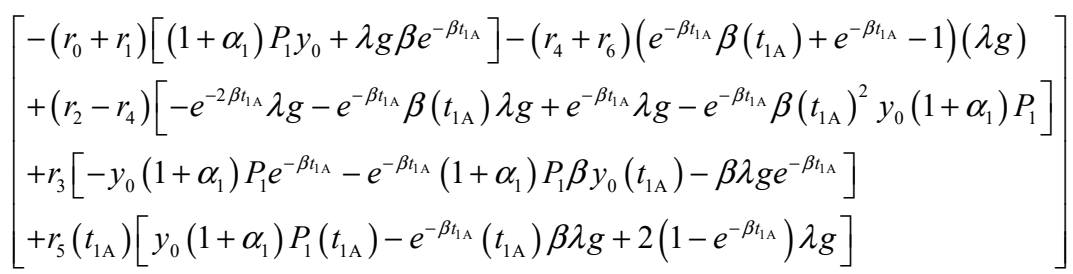

and

$$
\begin{aligned}
& \frac{d^{2} E\left[\operatorname{TCU}\left(t_{1 \mathrm{~A}}\right)\right]}{d\left(t_{1 \mathrm{~A}}\right)^{2}}=\frac{\left(1+\alpha_{1}\right) \lambda P_{1}}{\left[\left(1+\alpha_{1}\right) P_{1}\left(t_{1 \mathrm{~A}}\right) y_{0}+\left(1-e^{-\beta t_{1 A}}\right) \lambda g\right]^{3}} .
\end{aligned}
$$

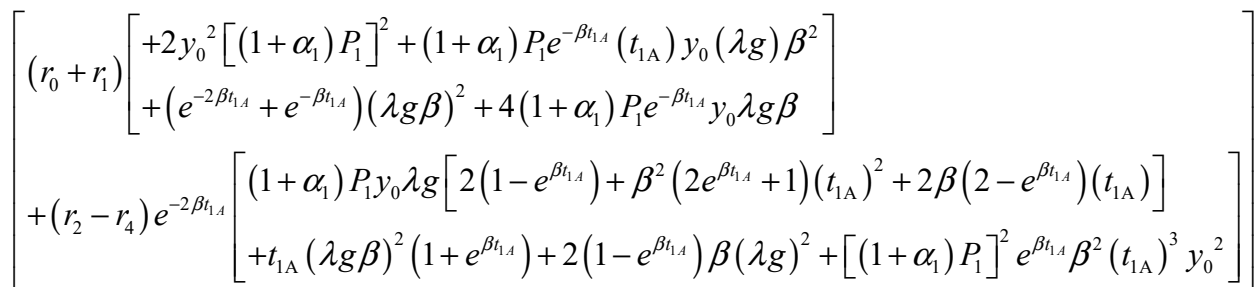

$$
\begin{aligned}
& +\left(r_{4}+r_{6}\right)(\lambda g)\left[\begin{array}{l}
2\left(e^{-2 \beta t_{1,}}-e^{-\beta t_{1, A}}\right)(\lambda g \beta)+\left(e^{-2 \beta t_{1, A}}+e^{-\beta t_{1, A}}\right)(\lambda g) \beta^{2}\left(t_{1 \mathrm{~A}}\right) \\
-2 y_{0}\left(1+\alpha_{1}\right) P+e^{-\beta t_{1,}} y_{0}\left(1+\alpha_{1}\right) P_{1}\left[\beta^{2}\left(t_{1 \mathrm{~A}}\right)^{2}+2 \beta\left(t_{1 \mathrm{~A}}\right)+2\right]_{1}
\end{array}\right] \\
& +r_{3}\left(e^{-\beta t_{1, A}}\right)\left[\begin{array}{l}
\left(1+\alpha_{1}\right) P_{1}\left(2+e^{-\beta t_{1, A}}\right) \beta^{2}\left(t_{1 \mathrm{~A}}\right) y_{0}(\lambda g)+2\left(1+\alpha_{1}\right) P_{1}\left(1+e^{-\beta t_{1, A}}\right) \beta y_{0}(\lambda g) \\
+(\lambda g \beta)^{2}\left(e^{-\beta t_{1, A}}+1\right)+y_{0}^{2}\left[\left(1+\alpha_{1}\right) P_{1}\right]^{2}\left[\beta^{2}\left(t_{1 \mathrm{~A}}\right)^{2}+2 \beta\left(t_{1 \mathrm{~A}}\right)+2\right]
\end{array}\right] \\
& +r_{5}(\lambda g)\left[\begin{array}{l}
4\left(e^{-2 \beta t_{1, A}}-e^{-\beta t_{1, A}}\right)\left(t_{1 \mathrm{~A}}\right)(\lambda g) \beta+\left(1+\alpha_{1}\right) P_{1} e^{-\beta t_{1,}}\left(t_{1 \mathrm{~A}}\right)^{3} y_{0} \beta^{2}-4 e^{-\beta t_{1, A}}(\lambda g) \\
+2 \lambda g e^{-2 \beta t_{1, A}}+\lambda g \beta^{2} e^{-2 \beta t_{1,}}\left(t_{1 \mathrm{~A}}\right)^{2}+\lambda g \beta^{2} e^{-\beta t_{1, A}}\left(t_{1 \mathrm{~A}}\right)^{2}+2 \lambda g
\end{array}\right]
\end{aligned}
$$

The first term on the RHS of Eq. (C-2) is positive, so $E\left[T C U\left(t_{1 \mathrm{~A}}\right)\right]$ is convex if the second term on the RHS of Eq. (C-2) is positive as well (i.e., if the following $\omega\left(t_{1 \mathrm{~A}}\right)>t_{1 \mathrm{~A}}>0$ holds). 


$$
\begin{aligned}
& -\left(r_{0}+r_{1}\right)\left[\left(e^{-2 \beta t_{1 A}}+e^{-\beta t_{1 A}}\right)(\lambda g \beta)^{2}+\left(1+\alpha_{1}\right) P_{1} y_{0}\left[2\left(1+\alpha_{1}\right) P_{1} y_{0}+4 \lambda g \beta e^{-\beta t_{1 A}}\right]\right] \\
& -\left(r_{2}-r_{4}\right)\left(1-e^{\beta t_{1 A}}\right)\left[2\left(1+\alpha_{1}\right) P_{1} y_{0}(\lambda g)+2 \beta(\lambda g)^{2}\right]\left(e^{-2 \beta t_{1 A}}\right) \\
& -2\left(r_{4}+r_{6}\right)(\lambda g)\left[-\left(1+\alpha_{1}\right) P_{1} y_{0}\left(1-e^{-\beta t_{1 A}}\right)+\left(e^{-2 \beta t_{1 A}}-e^{-\beta t_{1 A}}\right)(\lambda g) \beta\right] \\
& -r_{3}\left(e^{-\beta t_{1 A}}\right)\left[2\left(1+e^{-\beta t_{1 A}}\right) y_{0}\left(1+\alpha_{1}\right) P_{1} \beta \lambda g+\left(1+e^{-\beta t_{1 A}}\right)(\lambda g \beta)^{2}+2 y_{0}^{2}\left[\left(1+\alpha_{1}\right) P_{1}\right]^{2}\right] \\
\omega\left(t_{1 \mathrm{~A}}\right)= & -2 r_{5}(\lambda g)^{2}\left(e^{-2 \beta t_{1 A}}-2 e^{-\beta t_{1 A}}+1\right) \\
& \left(r_{0}+r_{1}\right)\left[\left(1+\alpha_{1}\right) P_{1}(\lambda g) e^{-\beta t_{1 A}} y_{0} \beta^{2}\right] \\
& +\left(r_{2}-r_{4}\right)\left(e^{-2 \beta t_{1 A}}\right)\left[\left(1+e^{\beta t_{1 A}}\right)(\lambda g \beta)^{2}+\left[\left(1+\alpha_{1}\right) P_{1}\right]^{2} e^{\beta t_{1 A}} \beta^{2} t_{1 \mathrm{~A}}^{2} y_{0}^{2}\right. \\
\left.+\left(1+\alpha_{1}\right) P_{1}(\lambda g) y_{0}\left[+4 \beta-2 e^{\beta t_{1 A}} \beta+2 e^{\beta t_{1 A}} \beta^{2} t_{1 \mathrm{~A}}+\beta^{2} t_{1 \mathrm{~A}}\right]\right] & >0 \\
& +\left(r_{4}+r_{6}\right)(\lambda g \beta)\left[y_{0}\left(1+\alpha_{1}\right) P_{1}\left[e^{-\beta t_{1 A}} \beta t_{1 \mathrm{~A}}+2 e^{-\beta t_{1 A}}\right]+\left[e^{-2 \beta t_{1 A}}+e^{-\beta t_{1 A}}\right] \lambda g \beta\right] \\
& +r_{3}\left(1+\alpha_{1}\right) P_{1}\left(e^{-\beta t_{1, A}}\right) y_{0}\left[\left(1+\alpha_{1}\right) P_{1} \beta^{2} t_{1 \mathrm{~A}} y_{0}+2 \lambda g \beta^{2}+\lambda g \beta^{2} e^{-\beta t_{1 A}}+2\left(1+\alpha_{1}\right) P_{1} \beta y_{0}\right] \\
& +r_{5}(\lambda g)\left[\left(1+\alpha_{1}\right) P_{1} y_{0} \beta^{2} e^{-\beta t_{1 A}} t_{1 \mathrm{~A}}^{2}+\beta \lambda g\left(\beta e^{-\beta t_{1 A}} t_{1 \mathrm{~A}}+\beta e^{-2 \beta t_{1, A}} t_{1 \mathrm{~A}}+4 e^{-2 \beta t_{1 A}}-4 e^{-\beta t_{1 A} A}\right)\right]
\end{aligned}
$$

\section{References}

Abdul Halim, M., Paul, A., Mahmoud, M., Alshahrani, B., Alazzawi, A.Y.M., Ismail, G.M. (2021). An overtime production inventory model for deteriorating items with nonlinear price and stock dependent demand. Alexandria Engineering Journal, 60(3), 2779-2786.

Adazabra, A.N., Viruthagiri, G., Shanmugam, N. (2018). Manufacture of lightweight clay bricks with improved thermal insulation properties via the incorporation of spent shea waste. Journal of Applied Research and Technology, 16(3), 186203.

Aouam, T., Kumar, K. (2019). On the effect of overtime and subcontracting on supply chain safety stocks. Omega, 89, 1-20.

Assia, S., Ikram, E.A., Abdellah, E.B., Moumen, D., Ahmed, E.B. (2020). A genetic algorithm and B\&B algorithm for integrated production scheduling, preventive and corrective maintenance to save energy. Management and Production Engineering Review, 11(4), 138-148.

Brahmi, A., Hadj-Alouane, A.B., Sboui, S. (2020). Dynamic and reactive optimization of physical and financial flows in the supply chain. International Journal of Industrial Engineering Computations, 11(1), 83-106.

Campbell, G.M. (2017). Time-staged overtime staffing for services with updated forecasts and availabilities. Decision Sciences, 48(4), 691-722.

Chiu, S.W., Chen, H-C., Lin, H-D. (2019). Optimal common manufacturing cycle length for a multi-product inventory system with rework and an outside contractor. International Journal for Engineering Modelling, 32(1), 1-16.

Chiu, Y-S.P., Chiu, V., Yeh, T-M., Wu, H-Y. (2020). Incorporating outsourcing strategy and quality assurance into a multiproduct manufacturer-retailer coordination replenishing decision. Mathematics, 8(12), Art. No. 02212.

Chiu, S.W., Chiu, T., Chiu, Y-S.P., Lin, H-D. (2021). Economic manufacturing quantity model with machine failure, overtime, and rework/disposal of nonconforming items. Management and Production Engineering Review, 12(1), 3-16.

DemiRel, T., Taskan, E. (2012). Multi-criteria evaluation of shifts and overtime strategies using choquet integral. Lecture Notes in Engineering Computer Sciences, 2198, 773-778.

Fontinha, R., Easton, S., Van Laar, D. (2019). Overtime and quality of working life in academics and nonacademics: The role of perceived work-life balance. International Journal of Stress Management, 26(2), 173-183.

Frank, M., Ostermeier, M., Holzapfel, A., Hübner, A., Kuhn, H. (2021). Optimizing routing and delivery patterns with multicompartment vehicles. European Journal of Operational Research, 293(2), 495-510.

Jeunet, J., Bou Orm, M. (2020). Optimizing temporary work and overtime in the Time Cost Quality Trade-off Problem. European Journal of Operational Research, 284, 743-761.

Johansson, L., Sonntag, D.R., Marklund, J., Kiesmüller, G.P. (2020). Controlling distribution inventory systems with shipment consolidation and compound Poisson demand. European Journal of Operational Research, 280(1), 90-101.

Gera, A.E. (2021). The Reliability of a system involving change points. International Journal of Mathematical, Engineering and Management Sciences, 6(1), 296-308.

Giri, B.C., Sharma, S. (2017). Integrated model for an imperfect production-inventory system with a generalised shipment policy, errors in quality inspection and ordering cost reduction. International Journal of Systems Science: Operations \& Logistics, 4(3), 260-274.

Gunasekaran, A., Goyal, S.K., Subash Babu, A., Ramaswamy, N. (1991). Effect of machine failures in a multi-stage multifacility and multi-product production-inventory system. International Journal of Systems Science, 22(2), $273-291$.

Hill, R.M. (1997). The single-vendor single-buyer integrated production-inventory model with a generalised policy. European Journal of Operational Research, 97(3), 493-499.

Keyvanshokooh, E., Shi, C., \& van Oyen, M.P. (2021). Online advance scheduling with overtime: A primal-dual approach. Manufacturing and Service Operations Management, 23(1), 246-266. 
Klašnja, N., Sremčev, N., Vukelić, D., Simeunović, N., \& Lazarević, M. (2019). Optimization of cable harness assembly systems based on Lean concept application. International Journal of Industrial Engineering and Management, 10 (1), $115-123$.

Kreng, V.B., \& Chen, F.T. (2007). Three echelon buyer - Supplier delivery policy - A supply chain collaboration approach. Production Planning \& Control, 18(4), 338-349.

Makis, V., \& Fung, J. (1998). An EMQ model with inspections and random machine failures. Journal of the Operational Research Society, 49(1), 66-76.

Martins, L.D.C., Gonzalez-Neira, E.M., Hatami, S., Juan, A.A., Montoya-Torres, J.R. (2021). Combining production and distribution in supply chains: The hybrid flow-shop vehicle routing problem. Computers and Industrial Engineering, 159, Art. No. 107486.

Mumford, K., Dowrick, S. (1994). Wage bargaining with endogenous profits, overtime working and heterogeneous labor. The Review of Economics and Statistics, 76(2), 329-336.

Nogueira, T.H., Bettoni, A.B., Mendes, G.T.D.O., dos Santos, A.G., Ravetti, M.G. (2020). Problem on the integration between production and delivery with parallel batching machines of generic job sizes and processing times. Computers and Industrial Engineering, 146, Art. No. 106573

Ongcunaruk, W., Ongkunaruk, P., Janssens, G.K. (2021). Genetic algorithm for a delivery problem with mixed time windows. Computers and Industrial Engineering, 159, Art. No. 107478.

Özdamar, L., Birbil, Ş.I., Portmann, M.C. (2002). Technical note: New results for the capacitated lot sizing problem with overtime decisions and setup times. Production Planning \& Control, 13(1), 2-10.

Pal, B., Sana, S.S., Chaudhuri, K. (2012). A three layer multi-item production-inventory model for multiple suppliers and retailers. Economic Modelling, 29(6), 2704-2710.

Ravulakollu, A.K., Urciuoli, L., Rukanova, B., Tan, Y-H., Hakvoort, R.A. (2018). Risk based framework for assessing resilience in a complex multi-actor supply chain domain. Supply Chain Forum: An International Journal, 19(4), $266-281$.

Salehi Amiri, S.A.H., Zahedi, A., Kazemi, M., Soroor, J., Hajiaghaei-Keshteli, M. (2020). Determination of the optimal sales level of perishable goods in a two-echelon supply chain network. Computers and Industrial Engineering, 139, Art. No. 106156

Soriano, J., Jalao, E.R., Martinez, I.A. (2020). Integrated employee scheduling with known employee demand, including breaks, overtime, and employee preferences. Journal of Industrial Engineering and Management, 13(3), 451-463.

Tolooie, A., Maity, M., Sinha, A.K. (2020). A two-stage stochastic mixed-integer program for reliable supply chain network design under uncertain disruptions and demand. Computers and Industrial Engineering, 148, Art. No. 106722

Ullah, M., Kang, C.W. (2014). Effect of rework, rejects and inspection on lot size with work-in-process inventory. International Journal of Production Research, 52(8), 2448-2460.

Villacís, S.A., Burneo. P.S. (2020). UAVs' efficient assembly: Lean Manufacturing implementation in an UAVs' Assembly Company. International Journal of Industrial Engineering and Management, 11(4), 237-252.

Wee, H.M., Yu, J., Chen, M.C. (2007). Optimal inventory model for items with imperfect quality and shortage back ordering. Omega, 35, 7-11. 


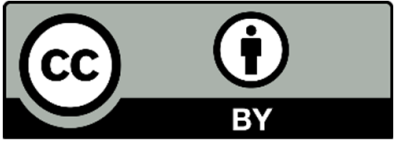

(C) 2022 by the authors; licensee Growing Science, Canada. This is an open access article distributed under the terms and conditions of the Creative Commons Attribution (CCBY) license (http://creativecommons.org/licenses/by/4.0/). 